\title{
Intensive intervention for fear of childbirth did not reduce requests for caesarean section but decreased duration of vaginal labour
}

Saisto T, Salmela-Aro K, Nurmi JE, et al. A randomized controlled trial of intervention in fear of childbirth. Obstet Gynecol 2001 Nov;98:820-6.

\section{QUESTION: In pregnant women with a fear of vaginal delivery, is intensive treatment} more effective than conventional treatment for reducing requests for caesarean section?

\section{Design}

Randomised \{allocation not concealed $*\}$, blinded $\{$ clinicians and data analysts $\}+, *$ controlled trial with follow up 3 months postpartum.

\section{Setting}

Outpatient clinic of the Department of Obstetrics and Gynecology, Helsinki University Central Hospital, Helsinki, Finland.

\section{Patients}

176 pregnant women referred for fear of vaginal delivery (mean age 32 y, mean 25 wk gestation, $51 \%$ nulliparous) who were at low obstetric risk and physically healthy. Exclusion criterion was a contraindication to vaginal delivery. Follow up was 100\%.

\section{Intervention}

Women were allocated to intensive $(n=85)$ or conventional $(n=91)$ treatment. Intensive treatment consisted of provision of information and conversation regarding previous obstetric experiences, feelings, and misconceptions; routine obstetric check ups; and cognitive treatment. A midwife appointment and visits to the obstetric ward were recommended for information about pain relief and possible interventions during labour and delivery. Conventional treatment consisted of standard information and routine obstetric check ups. Both groups received written information about the pros and cons of vaginal delivery and caesarean section, and pain relief offered at the hospital.

\section{Main outcome measures}

Reduction in requests for caesarean section at last obstetric appointment before delivery and duration of vaginal labour.

\section{Main results}

Analysis was by intention to treat. At baseline, 58 women (68\%) (32 multiparous) in the intensive treatment group and 59 women (65\%) (35 multiparous) in the conventional treatment group requested a caesarean section. In these women, groups did not differ for reduction in requested caesarean sections at the last obstetric appointment for all women and when analysed by parity (table). Mean duration of vaginal labour was shorter in the intensive group than in the conventional group $(6.8 \mathrm{~h} v 8.5 \mathrm{~h}, \mathrm{p}=0.04)$.

\section{Conclusions}

In pregnant women with a fear of vaginal delivery, intensive and conventional treatment groups did not differ for reduction in requested caesarean sections at last obstetric appointment before delivery. Mean duration of vaginal labour was shorter in the intensive treatment group.

*See glossary.

$\dagger$ Information provided by author.

Sources of funding: Signe and Ane Gyllenberg Foundation; Emil Aaltonen Foundation; Helsinki University Central Hospital; Academy of Finland.

For correspondence: Dr T Saisto, Helsinki University Central Hospital, Helsinki Finland. terhisaisto@hus.fi

Intensive $v$ conventional treatment for fear of vaginal delivery at the last obstetric appointment before delivery:

\begin{tabular}{lcccc} 
C-section request & Intensive & Conventional & RRR (95\% Cl) & NNT \\
All & $34 \%$ & $44 \%$ & $22 \%(-23$ to 51$)$ & Not significant \\
\hline Multiparous & $34 \%$ & $51 \%$ & $33 \%(-17$ to 63$)$ & Not significant \\
\hline & & & RRI (Cl) & NNH \\
Nulliparous & $35 \%$ & $33 \%$ & $3.8 \%(-51$ to 125$)$ & Not significant \\
\hline
\end{tabular}

$\neq C$-section=caesarean section. Other abbreviations defined in glossary; RRR, RRI, NNT, NNH, and Cl calculated from data provided by author.

\section{COMMENTARY}

Saisto et al have undertaken an important study attempting to reduce fear of childbirth. $6-10 \%$ of women report fear sufficient to lead to somatic complaints and poor concentration. ${ }^{1}$ Maternal anxiety affects fetal well being ${ }^{2}$ and increases the rates of caesarean section and postnatal depression.

Although the more intensive treatment (five 45 min sessions) with an obstetrician trained in cognitive therapy plus 90 minutes with a midwife did not reduce requested caesarean section rates more than conventional treatment (two 45 min sessions with the obstetrician), duration of labour was approximately $20 \%$ shorter in the intensive treatment group. Birth related concerns in the intensive treatment group may be reduced between baseline and before childbirth, but follow up for this outcome was $<80 \%$.

Saisto $e t$ al showed a reduction in caesarean requests with just 2 sessions from an obstetrician, and extra input did not seem to bring any further reduction in such requests. Women receiving intensive treatment reported less fear of the obstetrician's unfriendly behaviour compared with women in the conventional treatment group who reported more fear of their obstetrician. This was, however, of borderline significance $(\mathrm{p}=0.054)$, and follow up was $<80 \%$. The childbirth experience was positive in both groups, although follow up for this outcome was $<80 \%$.

This study by Saisto $e t a l$ showed that attention and concern from an attendant during pregnancy can have a positive effect on childbirth similar to interventions during labour. ${ }^{3}$ Similar results should be possible elsewhere in the world, although it is not clear whether training in cognitive treatment is critical, nor whether the counselling could be as well done by a midwife. I hope studies such as this will help to humanise care in pregnancy and childbirth by showing that the use of technology is not the only way forward. Gavin Young, MA, MB, BS Temple Sowerby

Penrith, Cumbria, UK

1 Jolly J, Walker J, Bhabra K. Subsequent obstetric performance related to primary mode of delivery. Br J Obstet Gynaecol 1999;106:227-32.

2 Wadhwa PD, Sandman CA, Porto M, et al. The association between prenatal stress and infant birth weight and gestational age at birth: a prospective investigation. Am J Obstet Gynecol 1993;169:858-65.

3 Hodnett ED. Caregiver support for women during childbirth. Cochrane Database Syst Rev 2002;(1):CD000199 